\title{
Are coronas cooling products?
}

\author{
Kai Sørensen
}

Metadolerites play a crucial role in the unravelling of the history of Precambrian crystalline terrains and it is therefore important to consider how they reflect the thermal history of the crust they intruded.

Metamorphic assemblages of little- or undeformed basic dykes often occur as coronas or reaction rims and are often interpreted as a result of reaction during cooling. Recent advocates of this interpretation are Griffin \& Heier (1973) and their cooling hypothesis has also been applied to basic dykes in Greenland. Some aspects of corona formation, which have not been considered, are important, and they will be briefly described here. A more comprehensive treatment is in progress.

Most coronas described in the literature (for example those treated by Griffin \& Heier) formed from reactions between plagioclase and either olivine or pyroxene (orthopyroxene or subcalcic clinopyroxene). These are the coronas treated here.

Two characteristics of these coronas seem particularly important for a geological interpretation of corona structures: (1) they occur abundantly in basic to ultrabasic rocks intruded into high grade metamorphic terrains, but have not, apparently, been found in their enclosing quartzo-feldspathic gneisses, (2) the corona forming reactions are often incomplete. The cooling hypothesis logically explains the first point and seems intuitively in accord with the second. It is appropriate to consider coronas by first addressing the first question, then to consider the kinetic significance of the structure and, finally, the kinetic significance of incomplete reaction.

\section{Occurrence or non-occurrence of coronas}

Three textural requirements have to be fulfilled in order for coronas to develop, (i) a considerable grain size reduction must take place, (ii) the reactant phases should be modally predominant, and (iii) there should be no more than two solid reactants. These requirements, taken together, prevent formation in most gneisses and are all fulfilled by coarse grained plutonites free from quartz. Different silica activities in plutonites and their host rocks will tend to enhance this difference in probability of corona formation. At silica activities less than one the stability fields of typical product assemblages (for example clinopyroxene + garnet $+\mathrm{SiO}_{2}$ ) will expand (Glassey \& Sørensen, in press), and a corona reaction may thus be thermodinamically possible in an undersaturated rock and at the same time impossible in surrounding, quartz-bearing gneisses. Textural and chemical reasons alone seem sufficient to explain the occurrence/non-occurrence problem of coronas (reaction rims). 


\section{Kinetic significance of coronas}

Two fundamentally different structures are found in coronas: single phase layers and multiphase layers (symplectites). Both structures indicate volume diffusion control and may be interpreted in analogy to two reaction mechanism models suggested for a simple displacive reaction: the 'Jost mechanism' for single phase layer structures (Jost, 1937) and the 'Wagner mechanism' for symplectite structures (Wagner, 1938). The symplectite structure and the fibrous habit of e.g. product orthopyroxene in some coronas can alternatively be seen as an expression of grain boundary diffusion. The structures of coronas leave little doubt of solid state diffusion control and Griffin \& Heier's (1973) analogy to a crystal growth mechanism cannot serve as an argument for reaction during cooling.

\section{Kinetic significance of incomplete reaction}

It seems natural to assume that the rate-limiting diffusion step in corona formation occurs within either plagioclase or garnet (and not orthopyroxene, clinopyroxene, amphibole, olivine, quartz or spinel), both minerals being frequently zoned. By comparing reactions with or without garnet and reactions with or without albite as a reactant phase it is concluded that diffusion within the plagioclase is the rate limiting step.

The above points have been raised to show the inadequacy of existing treatment of coronas (reaction rims), in as much as they do not consider the significance af these questions. It can be concluded that the diffusion data necessary for a solution of the problem is lacking, and, consequently, coronas should not uncritically be accepted as evidence for crystallization during cooling. and, furthermore, without the proper flux-equations formulated, it is not even clear what the relevant diffusion data are.

\section{References}

Glassley, W. E. \& Sørensen, $\mathrm{K}$. in press: Constant $P_{\mathbf{S}}-T$ amphibolite to granulite facies transition in Agto (West Greenland) metadolerites: implications and applications. J. Petrol.

Griffin, W. L. \& Heier, K. S. 1973: Petrological implications of some corona structures. Lithos 6, 315-335.

Jost, W. 1937: Diffusion und chemische Reaktion in festen Stoffen. Dresden: Steinkopff-Verlag.

Wagner, C. 1938: The mechanism of double decomposition in reactions in the solid phase. $Z$. anorg. allgem. Chemie 236, 320-338.

Geologisk Institut, Aarhus Universitet, DK-8000 Århus C, Denmark. 